\title{
¿HACIA DÓNDE VAMOS?
}

\section{To where are we going?}

Los tiempos cambian y las instituciones no sólo deben adaptarse a ellos sino que, idealmente, anticiparlos o promoverlos. Una de las misiones más importantes que hemos decidido emprender, como Directorio de la Sociedad de Cirujanos de Chile (SCCH), durante este periodo de dos años, es la modernización de nuestra Sociedad. ¿Pero qué significa modernizar? ¿Cuál es nuestro concepto? Hay muchas tareas por emprender, pero desde el año pasado que estamos revisando no sólo nuestro quehacer, sino el entorno en el que nos desempeñamos como cirujanos.

Hemos revisado la parte administrativa del personal que trabaja en la Sociedad, para elaborar una politica, previamente inexistente, de contratos, sueldos y beneficios clara, estable y conocida por todos, que ha sido aprobada por el Directorio y que comunicaremos oportunamente.

El ámbito académico y científico es una de nuestras principales tareas, por lo que estamos modernizando nuestras reuniones mensuales, haciéndolas más interesantes. El cambio del día de la reunión de miércoles en la tarde, a sábado en la mañana, ha mejorado la asistencia en forma significativa. Hemos realizado, en conjunto con los Departamentos, múltiples cursos en Santiago y regiones con interesantes temas y gran asistencia. Además realizaremos, por primera vez un curso con la Sociedad de Gastroenterología, gratuito para nuestros socios, el que se llevará a cabo en julio de este año.

Implementaremos, a contar de este año, un sistema de créditos para todas nuestras actividades científicas, con certificación anual que será un paso importante para la recertificación del año 2015.

Las guías clínicas están en proceso con, a lo menos, la inclusión de cuatro patologías prevalentes por Departamento, de manera de contar con estándares nacionales que faciliten nuestra actividad quirúrgica.

Acogiendo algunas críticas sobre la objetividad y diferencias de criterio en la selección de trabajos aceptados para presentación en el congreso anual es que implementaremos un sistema de Evaluadores, en su mayoría propuestos por los Departamentos, que efectúen dicha labor en forma objetiva y confiable. Para ello se dictarán tres cursos para uniformar criterios, lo que asegurará un estándar común en la aceptación de resúmenes en cualquiera de las categorías que hemos predefinido.

Completamos un año de trabajos y estudios en el Comité Científico. Como consecuencia de ello hemos cambiado el sistema de premiación anual haciéndolo más moderno y motivador.

Realizamos un estudio, a través de encuestas, sobre la realidad del ejercicio de la cirugía en Chile, lo que demandó un gran esfuerzo. Hemos tenido algunas sorpresas en relación a los resultados, como por ejemplo la escasa disponibilidad de ecografía, laparoscopía y endoscopia en los servicios de urgencia de nuestro país. Las condiciones de trabajo en muchos centros son tan malas como poco seguras y muchos cirujanos deben operar sin la asistencia de otro profesional debidamente calificado, exponiéndose a problemas legales y peor aún, poniendo en peligro la vida de nuestros pacientes.

La infraestructura de los hospitales y de muchas clínicas es deficiente y las facilidades para el perfeccionamiento es escasa o nula en algunos centros asistenciales.

Esta realidad, reflejada a través de las encuestas, fue refrendada en el ler. Encuentro Nacional realizado en nuestro país de Jefes de Servicios y Departamentos de Cirugía y Urgencia, en el que se presentaron 15 ponencias sobre las condiciones de servicios quirúrgicos de distintos centros públicos, privados, universita- 
rios e institucionales a lo largo de nuestro territorio. Tenemos la información, que pretendemos hacer llegar a las autoridades correspondientes, para tener un plan de implementación de mejoras, en las que nuestra Sociedad tiene mucho que decir.

Este año realizamos en conjunto con la Sociedad Panamericana de Trauma un excelente congreso con más de 1.500 participantes en la ciudad de Santiago, ampliamente reconocida por su calidad científico-social.

Nuestra revista, parte del índice ISI desde hace 4 años, al incorporar la modalidad electrónica, ha aumentado en forma significativa su impacto, recibiendo una cantidad sorprendente de visitas diarias a través de internet. Dicha página web está aun en sus inicios y esperamos una mejora continua de su accesibilidad, forma y fondo. Una vez logrado ello, reemplazará al menos a la mitad del tiraje actual de la revista en papel.

En noviembre, entre el 18 y el 21 de este año, llevaremos a cabo el Congreso Anual en la ciudad de Antofagasta, después de más de 20 años. Su importante atractivo turístico hacia la zona de San Pedro de Atacama, sus excelentes playas y muy buena gastronomía, serán un incentivo más para participar en él. Estamos planificando atractivos cursos de actualización, uno de ellos sobre complicaciones en cirugía abdominal. También realizaremos el $2^{\circ}$ Encuentro Nacional de Jefes de Servicio, el que al igual que el 2013, será abierto a todas los que desean asistir.

Una sociedad cientifica precisa financiamiento acorde con sus actividades. Desafortunadamente la alta morosidad existente nos impide hacer avances más rápidos en diferentes áreas de interés, por lo que apelamos a vuestra conciencia para solucionar este problema.

Hemos organizado a los Residentes de Cirugía en una nueva estructura societaria que los congrega, con el fin de acoger sus inquietudes y demandas para, así puedan integrarse precozmente, una vez finalizada su formación, como miembros activos de nuestra Sociedad. Estamos implementando un sistema de beneficios para ellos que haga que esta propuesta sea lo más atractiva posible.

Nos hemos abierto más a las regiones, aumentando significativamente las actividades, no sólo realizadas fuera de la capital sino que con participación activa de nuestros miembros de regiones, en la planificación de los mismos.

Este año habrá elección de Presidente y Directorio de la SCCH. Tenemos nuevo reglamento de elecciones, claro y trasparente, que permite una participación más informada, democrática y pluralista en las decisiones $y$ en definir el futuro de la Sociedad; los candidatos deberán presentar los diferentes programas de trabajo en nuestra página web, facilitando la decisión al momento de votar.

Vamos hacia una Sociedad de Cirujanos moderna y participativa, con una voz que debe ser escuchada y con actividades que responden a los intereses de nuestros miembros, lo que debe traducirse en una cada vez mejor atención de nuestros pacientes.

Estamos haciendo cambios importantes. Te invitamos a sumarte con propuestas que reflejen tus intereses, con espíritu crítico y emprendedor.

Mario Uribe M.

Presidente

Sociedad de Cirujanos de Chile 